\title{
Containing Loss Risk in a Low Inertia GB Power System
}

\author{
*Marcel Nedd, Keith Bell, Campbell Booth \\ Electronic and Electrical Engineering \\ University of Strathclyde \\ Glasgow, UK \\ *marcel.nedd@strath.ac.uk
}

\begin{abstract}
There is a reduction in the percentage penetration of synchronous machines within the GB power system; leading to a decrease in inertia, and an increase in system rate of change of frequency $(\mathrm{RoCoF})$ following a frequency event. This raises the challenge of containing frequency deviations within the relevant operational limits. As a result, steps need to be taken by the system operator to manage the risk to system security. In order to better understand this risk, this paper presents the challenge in light of the changing energy landscape and the current and future frequency response services available to contain frequency deviations. Although frequency response services may be capable of containing some events within frequency limits, in low inertia scenarios these responses alone are not capable of containing excursions within practical RoCoF limits. Consequently, further action must be taken to ensure system security. The system operator currently employs an interim solution of limiting the largest loss risk, depending on system inertia and the RoCoF limit. While this is suitable in the short-term, it is unlikely that this option will be viable in the future.
\end{abstract}

Keywords-frequency response; frequency containment; loss risk; low inertia; RoCoF

\section{INTRODUCTION}

The inertia of a power system is an inherent capability that affects the rate of change of frequency (RoCoF) following a system event [1, 2]. Traditionally, inertia has been made available due to transmission connected synchronous machines; however, in Great Britain (GB) the percentage of synchronous machines in the power system is reducing [3, 4], while the penetration of technologies such as wind and solar power, which in their majority are converter connected, is increasing. These converter connected technologies, also referred to as non-synchronous technologies, are connected via a solid-state electronic converter and do not have the same inherent capability of providing inertia to the system $[5,1]$.

The relationship between system inertia, Hsys, and RoCoF, $(\mathrm{df} / \mathrm{dt})$, is shown in (1) where $\mathrm{dP}$ is the power imbalance and fo is the nominal frequency. It can be seen that as system inertia reduces, the RoCoF, increases for a given power imbalance.

$$
d P=\left(\frac{2 \times H_{s y s}}{f_{o}}\right) \times\left(\frac{d f}{d t}\right)
$$

If the RoCoF following a frequency deviation is too high, it increases the risk of cascading frequency events, as a result of the tripping of RoCoF relays; these relays, such as the loss of mains (LoM) protection relays, are designed to open relevant circuits when the system RoCoF reaches a given limit [6]. This raises concerns regarding the behaviour of the power system in the first few seconds following a mismatch of power supply and demand. There are operational limits, relating to both RoCoF and minimum or maximum frequency excursions that the GB system operator (SO) must ensure are respected in the event of a credible disturbance. In a system with decreasing penetration of synchronous generation the challenge of complying with these limits increases.

In Section II, this paper will discuss the provision of frequency response services in GB. Following this, Section III will present two studies that investigate the containment of loss risk in the GB power system. Lastly, Section IV contains a discussion of the findings and an outline of the next steps of the research.

\section{FREQUENCY RESPONSE IN GB}

Fig. 1 below is an illustration of the current GB frequency response services showing primary, secondary, and reserve. Fig. 2 illustrates the operating timescales of primary, secondary, high and enhanced frequency response services, while Table I provides the technical definitions of these services. With the exception of enhanced frequency response (EFR), these responses can be dynamic or non-dynamic. Dynamic frequency responses are response services that continuously track frequency deviations and provide the required response. Non-dynamic frequency responses are frequency-triggered services that include dynamic and static response; i.e., when a frequency trigger is reached these services can either continuously or discreetly respond to frequency deviations. Under European Network of Transmission System Operators for Electricity (ENTSO-E) definitions, primary response is roughly equivalent to frequency containment reserve, secondary response is equivalent to restoration reserve and reserve dispatch recovery is equivalent to replacement reserve [7].

This work has been supported through the EPSRC Centre for Doctoral Training in Future Power Networks and Smart Grids (EP/L015471/1). 


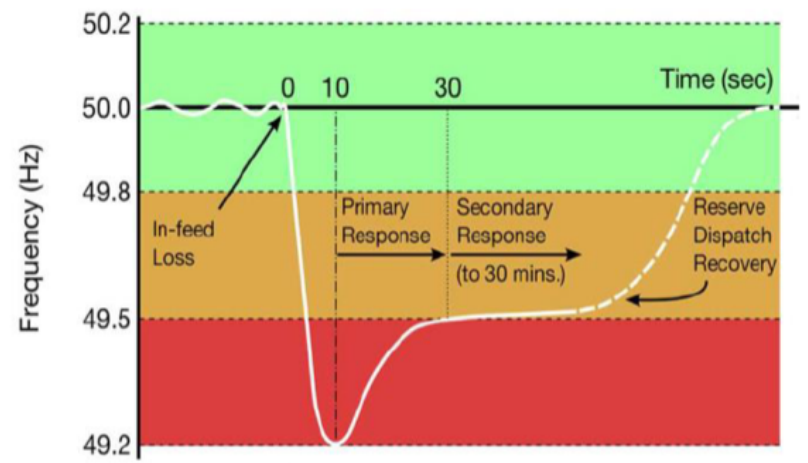

Fig. 1: Illustrating the operation of GB frequency response services [8].

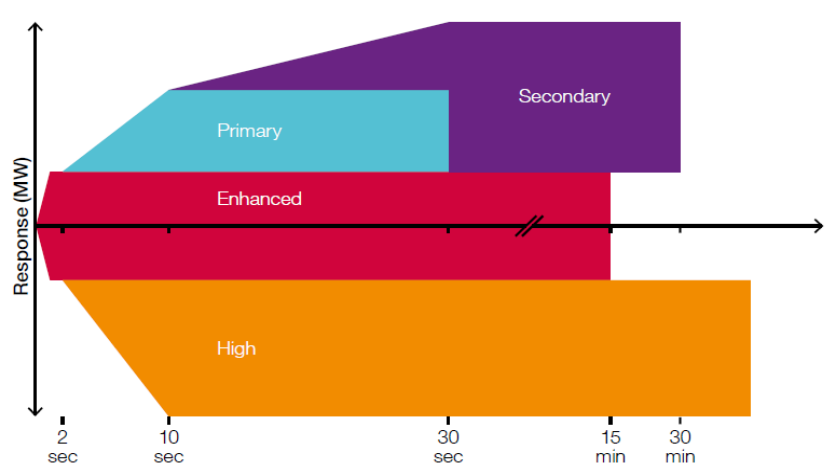

Fig. 2: Current GB frequency response services [9].

TABLE I. OVERVIEW OF FREQUENCY RESPONSE SERVICES $[9,10]$

\begin{tabular}{|c|l|}
\hline Service Name & \multicolumn{1}{|c|}{ Technical Definition } \\
\hline $\begin{array}{c}\text { Primary Frequency } \\
\text { Response }\end{array}$ & $\begin{array}{l}\text { Full delivery of active power response } 10 \text { seconds } \\
\text { after the event with a } 2 \text { second delay and } \\
\text { sustained for a further } 20 \text { seconds. }\end{array}$ \\
\hline $\begin{array}{c}\text { Secondary } \\
\text { Frequency Response }\end{array}$ & $\begin{array}{l}\text { Full delivery of active power response 30 seconds } \\
\text { after the event and sustained for 30 minutes. }\end{array}$ \\
\hline $\begin{array}{c}\text { High Frequency } \\
\text { Response }\end{array}$ & $\begin{array}{l}\text { Full delivery of active power response } 10 \text { seconds } \\
\text { after the event with a 2 second delay and } \\
\text { sustained indefinitely. }\end{array}$ \\
\hline $\begin{array}{c}\text { Enhanced } \\
\text { Frequency Response }\end{array}$ & $\begin{array}{l}\text { Full delivery of response for a } 0.5 \mathrm{~Hz} \text { change in } \\
\text { frequency and sustained for } 15 \text { minutes. }\end{array}$ \\
\hline
\end{tabular}

Conventional providers of dynamic frequency response services are synchronous generators. On the other hand, nonsynchronous generators are increasingly displacing synchronous generators. Under the status quo, the displacement of synchronous generation reduces system inertia and increases RoCoF during a power imbalance. Furthermore, the displacement results in simultaneously reducing the primary frequency response availability in terms of capacity and increasing primary frequency response requirement under traditional service arrangements, due to the higher RoCoF experienced for a given loss event. Consequently, the reduction in system inertia leads to concerns regarding containing a frequency event within the acceptable limits both in terms of RoCoF and frequency.

\section{SYSTEM STUDIES}

An in-house developed single bus model representing the GB transmission system [11] in DigSILENT PowerFactory is used for the present system study. The study applies the following assumptions:

- All the inertia in the system is represented in the inertia of the synchronous generators and no further inertia is provided by demand.

- Demand provides an inherent active power response of $2.5 \% / \mathrm{Hz}[8]$.

- An inertia constant of 5 seconds is assumed for all synchronous generators.

- Generation is split into synchronous and nonsynchronous generation.

- Generation is further divided into flexible and nonflexible, where flexible generation can provide active power response, while non-flexible cannot.

- The response provided by flexible units is modeled as dynamic response. Flexible units are $75 \%$ loaded with response provided by $50 \%$ of the headroom [12].

- A normal loss of in-feed event of $1 \mathrm{GW}$ of interconnector supply in modeled with a maximum frequency deviation of $-0.5 \mathrm{~Hz}$ from nominal $50 \mathrm{~Hz}$ [13, 14, 10].

- Unless otherwise stated system demand is $20 \mathrm{GW}$.

In $\mathrm{GB}$, the SO published the system operability framework (SOF) 2016 [9]. This document highlights, among other factors, the limits to largest loss of demand or generation, which are constrained by the system inertia and RoCoF limit. The RoCoF limit in GB is $\pm 1 \mathrm{~Hz} / \mathrm{s}$ for all new and existing generators with a delay of $500 \mathrm{~ms}$ [21,22]. The original document gave existing generators until the 1st July 2016 to make the relevant changes, however there is about $6 \mathrm{GW}$ of distributed generation that are still using relays that could activate if RoCoF exceeds $\pm 0.125 \mathrm{~Hz} / \mathrm{s}$ [9]. This is significant since RoCoF relays are widely used in the UK and Ireland, in loss of mains (LOM) protection for distributed generation [15, 16]. Consequently, due to the $6 \mathrm{GW}$ of distributed generation still using the $\pm 0.125 \mathrm{~Hz} / \mathrm{s}$ RoCoF setting, $\pm 0.125 \mathrm{~Hz} / \mathrm{s}$ is the practical RoCoF limit in the GB power system, leading to a need to manage RoCoF within this limit during a frequency event.

\section{A. Containing Normal Loss Risk Within $\pm 0.5 \mathrm{~Hz}$ of Nominal Frequency with a $\pm 0.125 \mathrm{~Hz} / \mathrm{s}$ RoCoF Limit}

The present study will investigate the performance of the frequency response services in the GB power system to contain a normal loss risk of $1 \mathrm{GW}$ when system post-fault inertia is 130 GVAs. The performance will be measured in terms of containment to the defined limits of both RoCoF and frequency during a power imbalance.

There are two factors that determine acceptable frequency behaviour during a power imbalance, the size of frequency deviation and RoCoF. Consequently, the system must be 
secured against the normal loss risk in terms of the frequency deviation and against the loss risk in terms of the RoCoF limit. In the case of a 130 GVAs system the loss risk defined by the $\pm 0.125 \mathrm{~Hz} / \mathrm{s}$ RoCoF limit is calculated using (1) to be a loss risk of $650 \mathrm{MW}$. When compared to the $1 \mathrm{GW}$ normal loss risk for a frequency deviation of $\pm 0.5 \mathrm{~Hz}$, the system must be secured against the smaller loss risk of $650 \mathrm{MW}$. However, in terms of generation a loss risk of $650 \mathrm{MW}$ requires curtailment of any single unit (generator or interconnector) supplying power at the normal loss of in-feed limit of $1 \mathrm{GW}$.

TABLE II. STUDY SCENARIOS FOR CONTAINING NORMAL LOSS RISK WITHIN \pm 0.5 Hz OF NOMINAL FREQUENCY WITH A \pm 0.125 Hz/S ROCOF LIMIT

\begin{tabular}{|c|l|}
\hline Title & \multicolumn{1}{|c|}{ Description } \\
\hline Scenario $A$ & $\begin{array}{l}\text { Loss risk is curtailed from 1 GW to 650 MW and } \\
\text { implemented as the simulated loss of interconnector supply } \\
\text { with primary response containing the frequency deviation. }\end{array}$ \\
\hline Scenario $B$ & $\begin{array}{l}\text { Loss risk is 1 GW and implemented as the simulated loss of } \\
\text { interconnector supply with no frequency response provision. }\end{array}$ \\
\hline Scenario $C$ & $\begin{array}{l}\text { Loss risk is 1 GW and implemented as the simulated loss of } \\
\text { interconnector supply with primary response and EFR } \\
\text { containing the frequency deviation. }\end{array}$ \\
\hline Scenario $D$ & $\begin{array}{l}\text { Loss risk is 1 GW and implemented as the simulated loss of } \\
\text { interconnector supply with primary response containing the } \\
\text { frequency deviation. }\end{array}$ \\
\hline
\end{tabular}

To illustrate the issues surrounding the containment of loss risk in a low inertia power system, four scenarios are investigated using the system model and assumptions previously defined, these scenarios are presented in Table II above. The scenarios illustrate what would happen if different actions were taken to address containment of frequency following a power imbalance. Table III is an overview of the observations from the study, investigating the individual scenarios, while Fig. 3 and 4 below show the frequency and RoCoF plots for scenarios A - D.

TABLE III. OVERVIEW OF STUDY SCENARIOS AND OBSERVATIONS

\begin{tabular}{|c|c|c|c|c|}
\hline Loss & A & B & C & D \\
\hline $\begin{array}{c}\text { RoCoF } \\
\text { Contained }\end{array}$ & Yes & \multicolumn{3}{|c|}{$1000 \mathrm{MW}$} \\
\hline $\begin{array}{c}\text { Frequency } \\
\text { Deviation } \\
\text { Contained }\end{array}$ & Yes & No & \multicolumn{2}{|c|}{ Yes } \\
\hline Inertia & \multicolumn{4}{|c|}{130 GVAs } \\
\hline $\begin{array}{c}\text { Response } \\
\text { Type }\end{array}$ & $\begin{array}{c}\text { Primary } \\
\text { Only }\end{array}$ & None & $\begin{array}{c}\text { Primary } \\
\text { and EFR }\end{array}$ & $\begin{array}{c}\text { Primary } \\
\text { Only }\end{array}$ \\
\hline
\end{tabular}

Only in scenario A is the system event contained within both frequency and RoCoF limits, even with EFR simulated in scenario C. Scenario B is modeled for reference to indicate the frequency behaviour if no action is taken to contain the event.

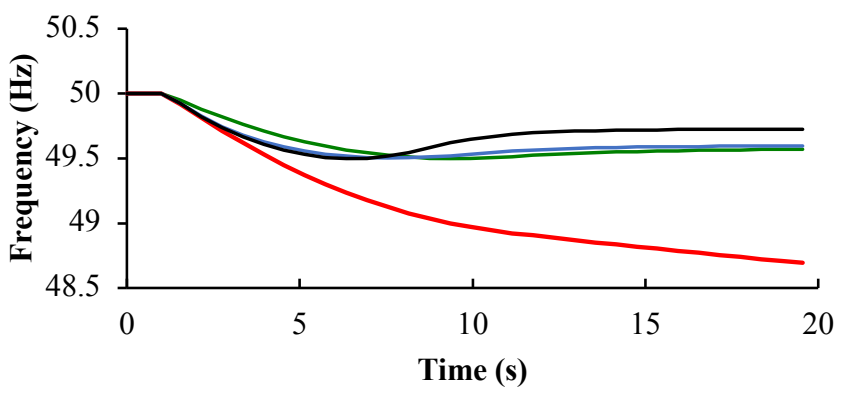

- Frequency - A $(\mathrm{Hz})$ Frequency - C (Hz)

Frequency - B (Hz)

Frequency - D (Hz)

Fig. 3: Frequency plots comparing the impact of different actions to meet operational limits for a system with $130 \mathrm{GVAs}$ of inertia.

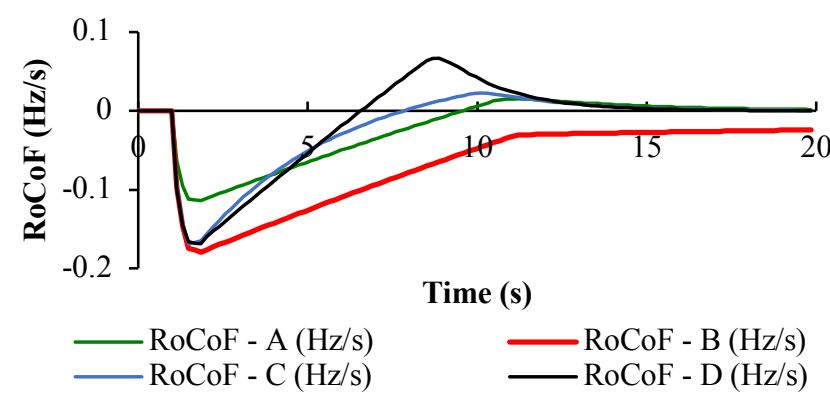

Fig. 4: RoCoF plots comparing the impact of different actions to meet operational limits for a system with $130 \mathrm{GVAs}$ of inertia.

\section{B. Containing Normal Loss Risk Within $\pm 0.5 \mathrm{~Hz}$ of Nominal Frequency and $a \pm 1 \mathrm{~Hz} / \mathrm{s}$ RoCoF Limit}

Considering the effort being made by the SO to change RoCoF relay settings to operate at $\pm 1 \mathrm{~Hz} / \mathrm{s}$ instead of \pm 0.125 $\mathrm{Hz} / \mathrm{s}$, the following study is conducted to investigate containment of loss risk using GB frequency response services at different system inertia, while remaining within the $\pm 1 \mathrm{~Hz} / \mathrm{s}$ RoCoF limit. The present study concerns the scenarios described in Table IV, and inherits the assumptions outlined in the previous study.

TABLE IV. STUDY SCENARIOS FOR CONTAINING NORMAL LOSS RISK WITHIN $\pm 0.5 \mathrm{~Hz}$ OF NOMINAL FREQUENCY AND A \pm 1 Hz/s ROCOF LIMIT

\begin{tabular}{|c|l|}
\hline Title & \multicolumn{1}{|c|}{ Description } \\
\hline Scenario 1 & $\begin{array}{l}\text { System inertia is 200 GVAs with EFR and TFR containing } \\
\text { the frequency deviation. }\end{array}$ \\
\hline Scenario 2 & $\begin{array}{l}\text { System inertia is 50 GVAs with EFR and TFR containing the } \\
\text { frequency deviation. }\end{array}$ \\
\hline Scenario 3 & $\begin{array}{l}\text { System inertia is 25 GVAs with EFR and TFR containing the } \\
\text { frequency deviation. }\end{array}$ \\
\hline Scenario 4 & $\begin{array}{l}\text { System inertia is 50 GVAs with EFR and a 1s service } \\
\text { containing the frequency deviation. }\end{array}$ \\
\hline Scenario 5 & $\begin{array}{l}\text { System inertia is 25 GVAs with EFR and a 1s service } \\
\text { containing the frequency deviation. }\end{array}$ \\
\hline
\end{tabular}

While still under development, a new concept for a postfault frequency response is proposed by the $\mathrm{SO}$, alongside other improvements to the provision of frequency response. This concept post-fault service (1s service) is the full delivery 
of response within 1 second with a maximum delay of 0.5 seconds and sustained for 20 minutes [17]. The 1s service will work alongside existing services with the intent of replacing traditional primary response. As such, the 1s service will also be considered in this study.

Table $\mathrm{V}$ provides an overview of the scenarios and observations of this study, while Fig. 5 and Fig. 6 show how these services perform at different levels of system inertia in response to the same $1 \mathrm{GW}$ loss of interconnector supply.

TABLE V. OVERVIEW OF STUDY SCENARIOS AND OBSERVATIONS

\begin{tabular}{|c|c|c|c|c|}
\hline & $\begin{array}{c}\text { Frequency } \\
\text { Deviation } \\
\text { Contained } \\
\end{array}$ & \begin{tabular}{|c} 
Frequency \\
Stable
\end{tabular} & Inertia & $\begin{array}{c}\text { Response } \\
\text { Type }\end{array}$ \\
\hline Scenario 1 & Yes & Yes & 200 GVAs & $\begin{array}{l}\text { EFR and } \\
\text { Primary }\end{array}$ \\
\hline Scenario 2 & No $(\approx 49 \mathrm{~Hz})$ & No & 50 GVAs & $\begin{array}{l}\text { EFR and } \\
\text { Primary }\end{array}$ \\
\hline Scenario 3 & No $(\approx 48.6 \mathrm{~Hz})$ & Yes & 25 GVAs & $\begin{array}{l}\text { EFR and } \\
\text { Primary }\end{array}$ \\
\hline Scenario 4 & Yes & Yes & 50 GVAs & $\begin{array}{l}\text { EFR and } \\
1 \mathrm{~s} \text { service }\end{array}$ \\
\hline Scenario 5 & Yes & No & 25 GVAs & $\begin{array}{l}\text { EFR and } \\
1 \mathrm{~s} \text { service }\end{array}$ \\
\hline
\end{tabular}

Upon consideration of the results of the study shown in Fig. 5 and 6 , and summarized in Table $\mathrm{V}$, it is seen that while RoCoF is contained within the $\pm 1 \mathrm{~Hz} / \mathrm{s}$ limit in scenarios $1-5$, frequency is contained in three of the five scenarios. Furthermore, two of those three scenarios indicate a stable frequency containment, with scenario 5 showing an instability that can lead to additional system events, exacerbating the impact of the loss of in-feed.

It should be noted that the benefit of a 1s service is apparent when comparing scenarios 2 and 4. In scenario 2, EFR and primary response are not sufficient to contain the frequency deviation, and also pose a risk of further instability; while in scenario 4, primary response is replaced with the 1 s service that together with EFR is capable of containing the frequency deviation, while keeping frequency stable. In addition, the $1 \mathrm{~s}$ service can contain the loss event with less than half the amount of response reserve that was dispatched in scenario 2 for primary response.

On the other hand, one of the risks that arises from the $1 \mathrm{~s}$ service entirely replacing primary response is shown at the very low system inertia of $25 \mathrm{GVAs}$ in scenario 5. This risk is increased as the loss risk tends towards the maximum loss risk of $1800 \mathrm{MW}$, defined in the National Electricity Transmission System Security and Quality of Supply Standard (NETS SQSS) [13]. Using (1), the mathematical calculation of RoCoF for a loss of $1 \mathrm{GW}$ at $50 \mathrm{GVAs}$ of inertia is $0.5 \mathrm{~Hz} / \mathrm{s}$. This RoCoF of $0.5 \mathrm{~Hz} / \mathrm{s}$ increases to $0.9 \mathrm{~Hz} / \mathrm{s}$ for a loss of $1.8 \mathrm{GW}$ at $50 \mathrm{GVAs}$. This suggests that an increase of loss of in-feed from $1 \mathrm{GW}$ to $1.8 \mathrm{GW}$ for a system inertia of $50 \mathrm{GVAs}$ in scenario 4 tends towards the results in scenario 5. Limiting the maximum output of the 1s service can reduce the risk of instability but this would also require the response reserve deficit to be met by other alternative frequency response services. Similarly, the loss risk can be curtailed but this incurs an additional cost that may not be sustainable in perpetuity.

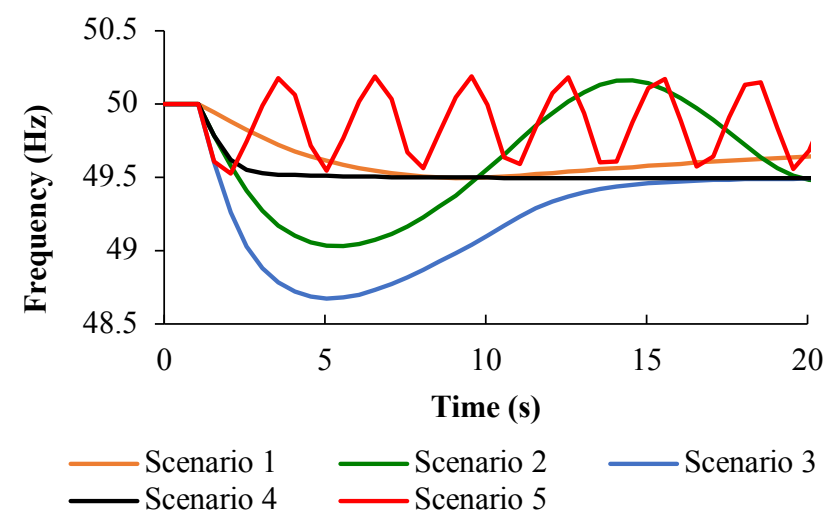

Fig. 5: Frequency plots comparing containment capabilities at different inertia levels with different response services.

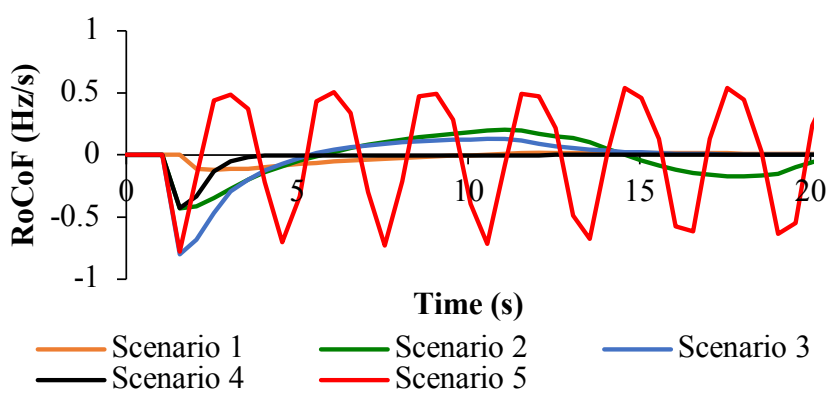

Fig. 6: RoCoF plots comparing containment capabilities at different inertia levels with different response services.

\section{DISCUSSION}

According to SOF by $2025 / 26$ the loss limit will be 650 MW about $25 \%$ of the time, in order to comply with the practical RoCoF limit of $\pm 0.125 \mathrm{~Hz} / \mathrm{s}$; leading to curtailment of loss risk to comply. National Grid in [5] puts the cost of curtailing loss risk at $£ 268 \mathrm{~m}$ per annum by 2020 , expected to increase year by year. Synchronous compensators are a potential solution that provides a range of system benefits [18]. It is plausible that implementation as the single solution to the issues of a very low (sub 75 GVAs) inertia GB power system would not be commercially viable, and indeed, the optimal solution may require a range of complimenting options.

While it is likely that the practical RoCoF limit will be relaxed in the future, there is no indication as to when or how this will happen, and at what cost. Meanwhile, the costs to system security are increased because the GB power system already experiences operational scenarios where loss risk has to be curtailed for system security. In the meantime existing synchronous generators that are considering decommissioning could convert their stations to synchronous compensators, providing inertia alongside other benefits. Similarly, there may be an incentive for new installations at key locations across the power system. However, locational placement raises additional questions regarding regional variations in service requirements. 
The paper shows that conventional frequency response services are unsuitable for adequately containing a normal loss risk as RoCoF approaches $\pm 1 \mathrm{~Hz} / \mathrm{s}$. Similarly, while the study indicates the benefits of $1 \mathrm{~s}$ service in comparison to primary response, it carries a risk at high $\mathrm{RoCoF}$ if the service completely replaces primary response. Although, the risk of the GB power system operating at low inertia levels sub 75 GVAs is extremely low before 2025 [9], it is possible that this may become more likely as the power system tends towards a greater percentage penetration of converter connected generation and accompanying closure of synchronous plant in the future. This raises the need for further study into how future frequency response services can be designed to accommodate such scenarios. In addition, while the 1s service as described in [17] is still under development, there are concerns raised by industry regarding the requirement to sustain a post-fault response for 20 minutes. This requirement is perceived to exclude wind only response services, while providing market signals for storage technologies - requiring more capital investments.

The next steps of this work will be to further investigate the challenges and costs of implementing solutions to the concerns raised in this paper that best fit the energy trilemma, especially regarding low inertia scenarios experiencing the maximum loss risk described by SQSS.

\section{REFERENCES}

[1] P. Tielens and D. V. Hertem, "The relevance of inertia in power systems," Renewable and Sustainable Energy Reviews, vol. 55, pp. 999-1009, 2016.

[2] P. Kundur, Power System Stability and Control, McGraw-Hill Inc., 1994.

[3] Department for Business, Energy and Industrial Strategy, "Implementing the end of unabated coal by 2025: Government response to unabated coal closure consultation," 2018.

[4] Department for Business, Energy and Industrial Strategy, "Coal generation in Great Britain: The pathway to a low carbon future - consultation document," 2016.

[5] National Grid, "Enhanced frequency control capability (EFCC)," $10 \quad 2014 . \quad$ [Online]. Available: https://tinyurl.com/h3k4rgw. [Accessed 0102 2017].

[6] A. D. Adrianti, "Risk Assessment Analysis to Find Optimum ROCOF Protection Settings," in 12th IET International Conference on Developments in Power System Protection (DPSP 2014), Copenhagen, 2014.

[7] Enstoe, "Network Code on Load-Frequency Control and Reserves," 28 June 2013. [Online]. Available: https://tinyurl.com/m2hkmeu. [Accessed 1905 2017].

[8] P. M. Ashton, C. S. Saunders, G. A. Taylor, A. M. Carter and M. E. Bradley, "Inertia estimation of the GB power system using synchrophasor measurements," IEEE Trans. on Power Systems, vol. 30, no. 2, pp. 701 - 709, 2015.

[9] National Grid, "System Operability Framework 2016," 2016. [Online]. Available: https://tinyurl.com/y9x8b9t5. [Accessed 1809 2017].

[10] National Grid, Enhanced Frequency Response Seminar, 2016.

[11] M. Nedd, Q. Hong, K. Bell, C. Booth and P. Mohapatra,
"Application of synchronous compensators in the GB transmission network to address protection challenges from increasing renewable generation," in 2017 CIGRE B5 Colloquium, Auckland, 2017.

[12] National Grid, Frequency Response Technical Sub-Group Report, vol. Version 1.0, 2011.

[13] National Grid, National Electricity Transmission System Security and Quality of Supply Standard, vol. Version 2.3, 2017.

[14] Ofgem , Letter: National Electricity Transmission System Security and Quality of Supply Standard: Normal Infeed Loss Risk (GSR015), 2014.

[15] P. Crolla, A. J. Roscoe, A. Dysko and G. M. Burt, "Methodology for testing loss of mains detection algorithms for microgrids and distributed generation using real-time power hardware-inthe-loop based technique," in 8th International Conference on Power Electronics - ECCE Asia, The Shilla Jeju, 2011.

[16] A. Dysko, "Loss of Mains Protection," [Online]. Available: http://tinyurl.com/mtt8mop. [Accessed 1105 2017].

[17] National Grid, "Future frequency response products," 042018. [Online]. Available: https://tinyurl.com/ybdbfa34. [Accessed 1004 2018].

[18] M. Nedd, C. Booth and K. Bell, "Potential solutions to the challenges of low inertia power systems with a case study concerning synchronous condensers," in 52nd International Universities Power Engineering Conference (UPEC), Heraklion, Greece, 2017.

[19] H. Urdal, "Impact on T\&D protection systems from low fault," in Substation Technology 2009: Analysing the Strategic and Practical Issues of Modern Substation, Birmingham, 2009.

[20] H. Urdal, R. Lerna, J. Zhu, C. Ivanov and A. Dahresobh, "System strength considerations in a converter dominated power system," IET Renewable Power Generation, vol. 9, no. 1, pp. $10-17,2015$.

[21] A. Johnson, "Grid code frequency response working group system inertia," 2010. [Online]. Available: https://tinyurl.com/hd3sk8u. [Accessed 0102 2017].

[22] Aurora, "Dash for interconnection," 02 2016. [Online]. Available: https://tinyurl.com/z44hsvh. [Accessed 2002 2017].

[23] Ofgem, "Electricity Network Innovation Competition: 2016 Funding Decision," 3011 2016. [Online]. Available: https://tinyurl.com/hk29g4j. [Accessed 2302 2017].

[24] National Grid, "Electricity Ten Year Statement 2016," 2016. [Online]. Available: https://tinyurl.com/ycxuzrox. [Accessed 1809 2017].

[25] National Grid, "Future Energy Scenarios," 2014. [Online]. Available: https://tinyurl.com/y73bp931. [Accessed 1809 2017].

[26] D. Boroyevich, I. Cvetković, D. Dong, R. Burgos, F. Wang and F. Lee, "Future Electronic Power Distribution Systems: A contemplative view," in 12th International Conference on Optimization of Electrical and Electronic Equipment, Brasov, 2010.

[27] D. Chakravorty, B. Chaudhuri and S. Y. R. Hui, "Estimation of Aggregate Reserve with Point-of-Load Voltage Control," IEEE Transactions on Smart Grid, vol. PP, no. 99, pp. 1 - 10, 25 April 2017.

[28] CIGRE, "Modelling and Aggregation of Loads in Flexible 
Power Networks," 02 2014. [Online]. Available: https://tinyurl.com/yc98b4wr. [Accessed 0811 2017].

[29] Ofgem, "Changes to the Distribution Code and Engineering Recommendation G59: Frequency chnages during large disturbances and their impact on the total system," 072014. [Online]. Available: https://tinyurl.com/hebprbe.

[30] Ofgem, Distribution Code: DC0079 - Frequency Changes during Large Disturbances and their Impact on the Total System, 2017.

[31] Ofgem, "Changes to the Distribution Code and Engineering Recommendation G59: Frequency changes during large disturbances and their impact on the total system," 23072014. [Online]. Available: https://www.ofgem.gov.uk/sites/default/files/docs/2014/07/gc0 035_authority_decision_0.pdf. [Accessed 0312 2015]. 